\title{
Pervasive Service Platform (PSP): Facilitating Pervasive Services
}

\author{
Fiona Mahon ${ }^{1}$, Jelena Mitic ${ }^{2}$, Micheal Crotty ${ }^{1}$, Kevin Doolin ${ }^{1}$, and Christoph Kuhmuench ${ }^{2}$ \\ ${ }^{1}$ Telecommunications Software \& Systems Group, Waterford Institute of Technology, Waterford, \\ Ireland \\ \{fmahon, mcrotty, kdoolin\}@tssg.org \\ ${ }^{2}$ Siemens, Munich \\ $\{$ christoph.kuhmuench, jelena.mitic\}@,siemens.com
}

\begin{abstract}
Pervasive computing is a new and emerging technology. The concept of pervasiveness and its deployment into reality are still not well aligned. This is because the vision of pervasiveness is a highly complex area that encompasses a large number of issues. The real vision of pervasiveness will never become a reality if everyone involved needs to repeatedly address all the issues involved in the concept. This paper focuses on the DAIDALOS Pervasive Service Platform (PSP) as an enabler of pervasive services. DAIDALOS is an EU Framework Programme 6 Integrated Project with 46 multinational partners from both the industry and academia. The paper details the strategy employed in DAIDALOS to facilitate Service Providers to offer pervasive services on top of the PSP. It argues that pervasiveness should be provided to Service Providers as part of the platform, instead of requiring pervasiveness to be totally embedded in the services themselves. This approach consequently opens up the service provision market to more players, driving the idea of a truly pervasive world. The paper gives an overview of the DAIDALOS platform as a pervasive service enabler, detailing how it facilitates pervasiveness by removing most of the work from the Service Providers themselves.
\end{abstract}

Index Terms-pervasiveness, pervasive service, pervasive definition

\section{INTRODUCTION}

Pervasive computing is a very high-level vision originally prescribed by Weiser where technologies "weave themselves into the fabric of everyday life until they are indistinguishable from it" [1]. To achieve such an end, many considerations have to be made technologically, socially, psychologically, financially, strategically and practically; each amounting to vast levels of investigation, research and development. This paper focuses on the technological practicalities of the provision of services and analyses the approach from a business perspective. The paper proposes a solution that brings the idea of offering pervasive services into a realistic realm, where pervasiveness is supplied by different players than those that provide the actual pervasive services. Provision of pervasiveness becomes a specialist area that service providers do not need to involve themselves with in a hands-on manner. Service providers need simply to use the pervasiveness provided to them by these specialist pervasive providers.

The vision of pervasiveness is vague and open to interpretation [3]. In DAIDALOS, a more concrete definition of what constitutes 'pervasiveness' has been formulated.

The following section of the paper discusses similar ideas from related projects in the context of the DAIDALOS approach. Section 3 defines the idea of pervasiveness and the way this is mapped to the platform architecture. Section 4 specifies the service model, and the way services are managed within our platform. The paper is concluded with the implementation results and conclusion.

\section{BACKGROUND}

While many of the hardware components like mobile and embedded devices, wearable artifacts etc., required to realize the vision of pervasive computing are available today, there is a lack of pervasive computing applications to run on these new platforms. This is mainly due to the fact that they are too hard to develop, deploy, and manage [4]. Apart from DAIDALOS, there are several projects going on that address this problem.

The Aura project [5] aims to provide the user with an invisible pervasive computing aura offering him, at any time, an optimal set of computing devices. It focuses on minimizing human computer interaction. DAIDALOS targets similar goals and extends these ideas with security and privacy concerns and detailed research on user preference management and context awareness.

The PalCom [6] project aims at providing an open architecture for palpable systems, i.e. systems that users can intuitively notice, understand, use and control in the most appropriate way according to the specific context. However, this work is based on a 'green field' approach and does not take existing technologies and services, e.g. based on Web 


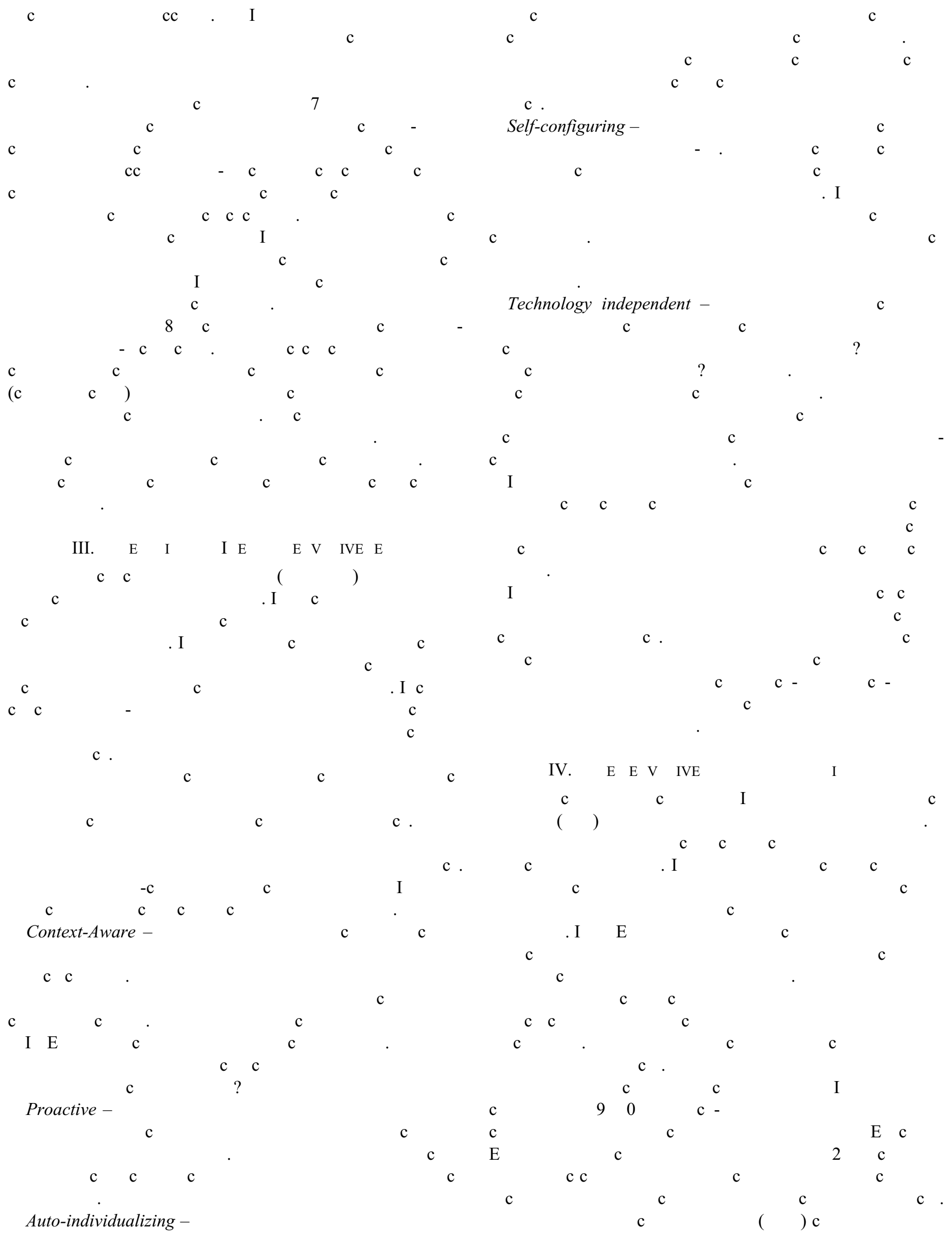



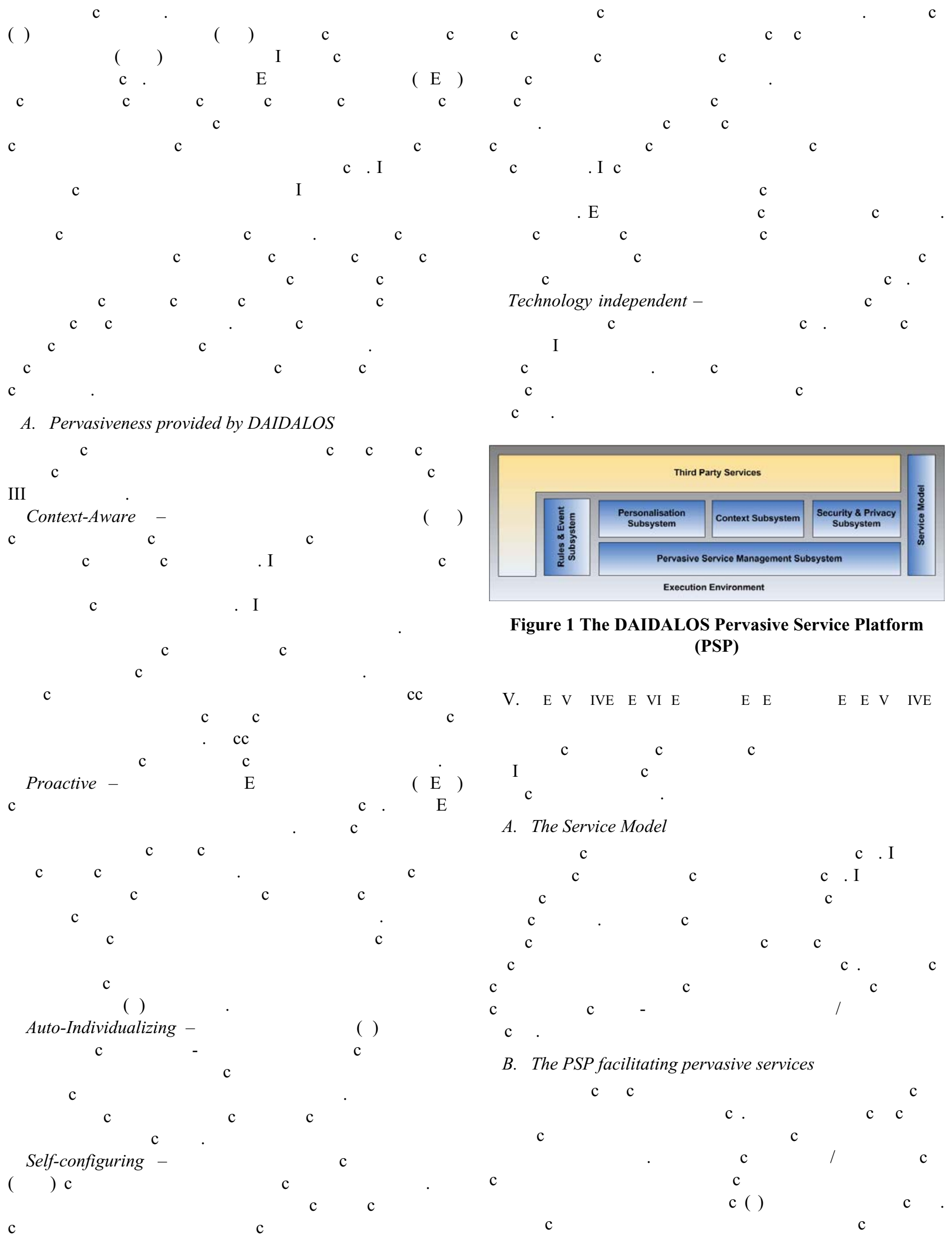

A. The Service Model

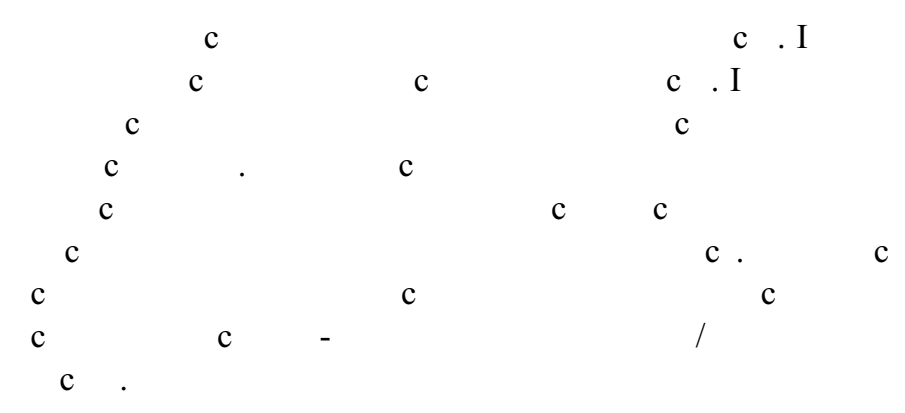

B. The PSP facilitating pervasive services c c

c

$\mathrm{c}$
Figure 1 The DAIDALOS Pervasive Service Platform (PSP)
V. E V IVE E VI E
E E
E E V IVE 
C

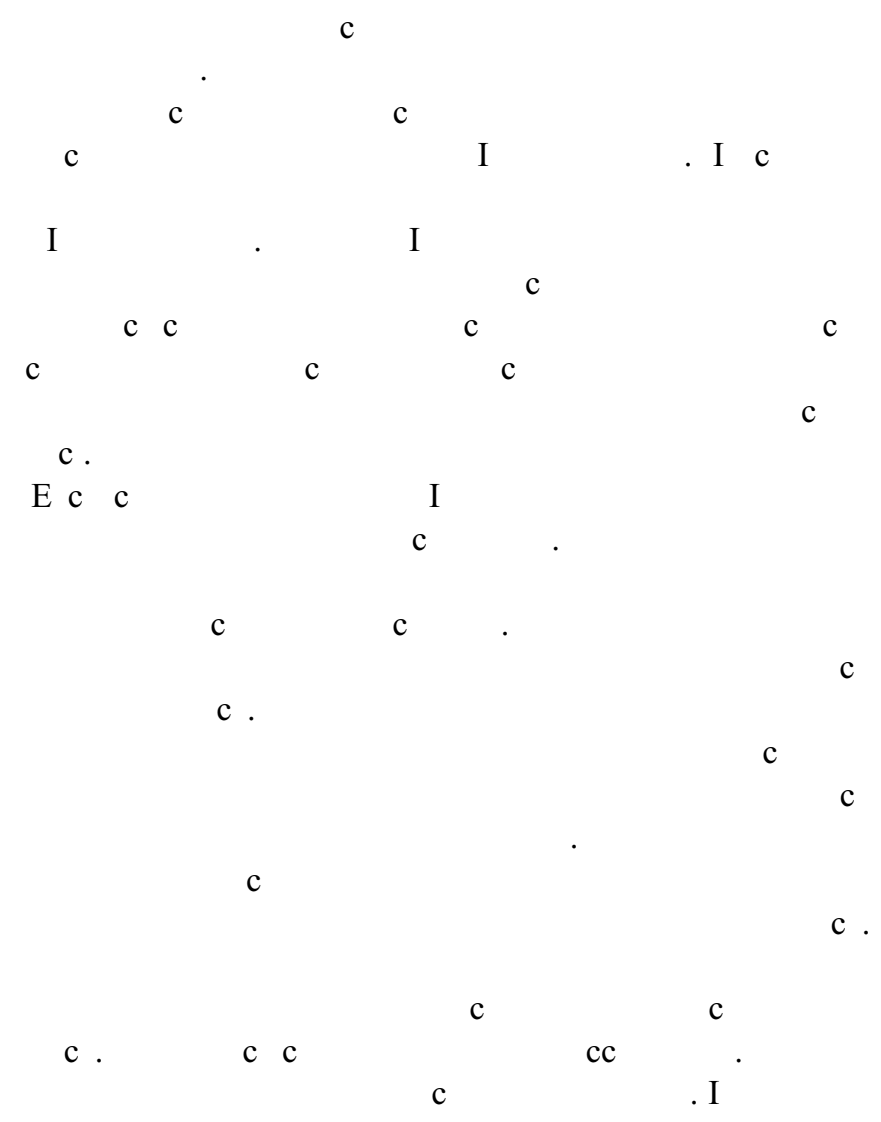

c

c.

2.

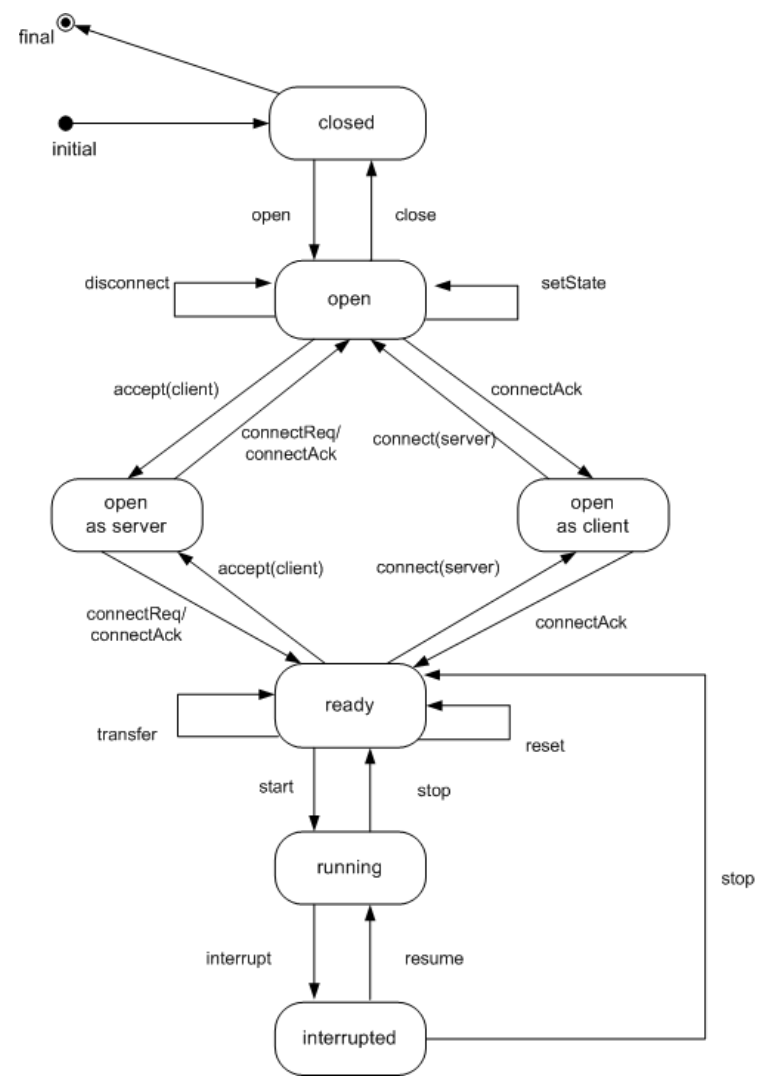

Figure 2 Service Model
E c

c

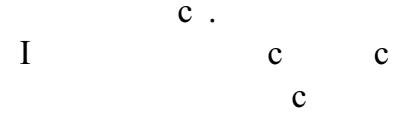

c

c<smiles></smiles>

c

c

c

c c.

c

c

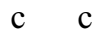

c

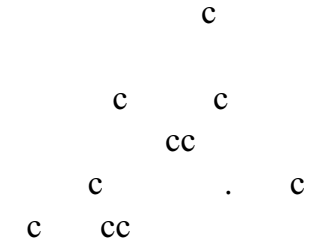

c.

c

cc

c

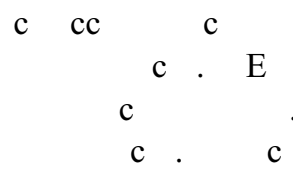

c

c 


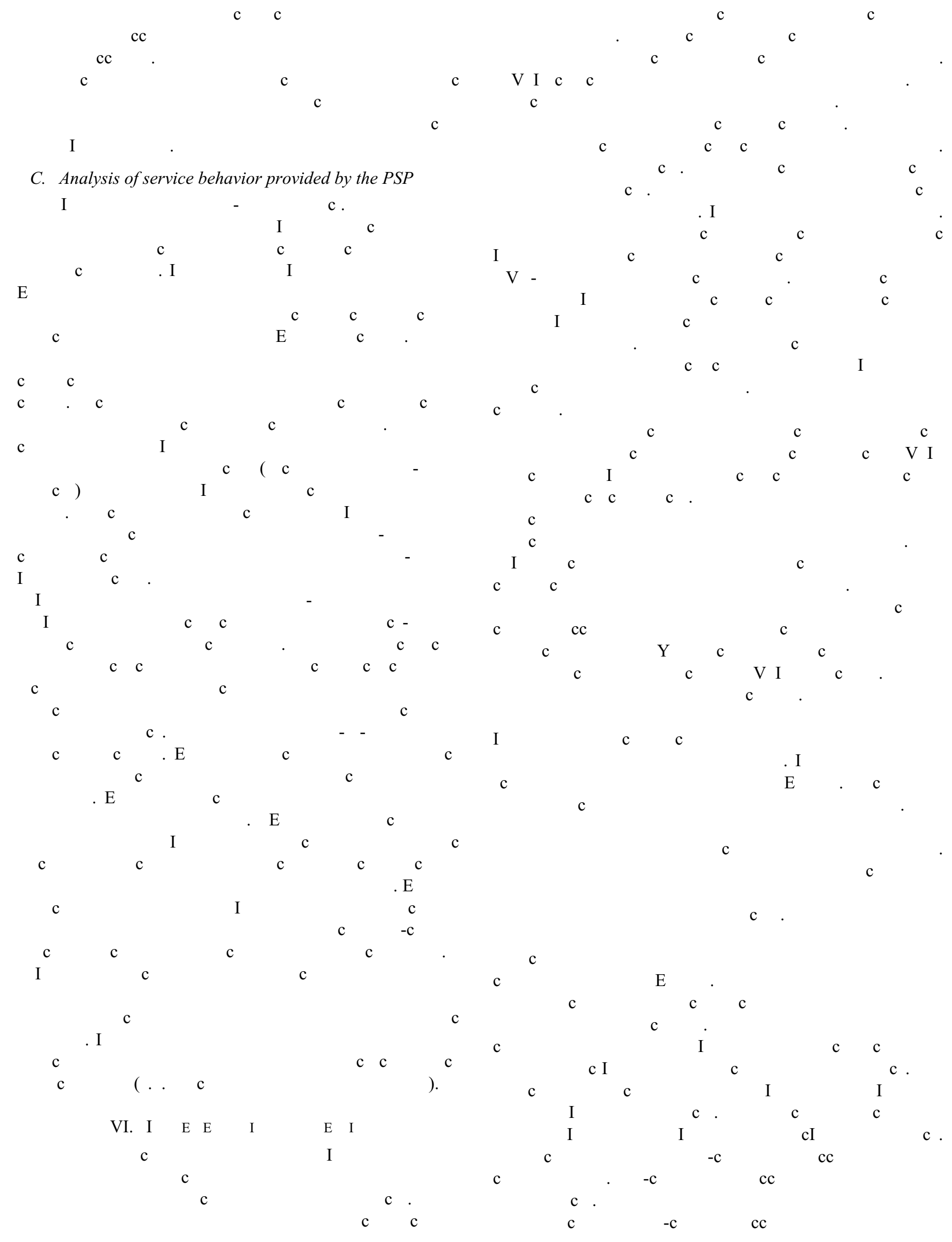




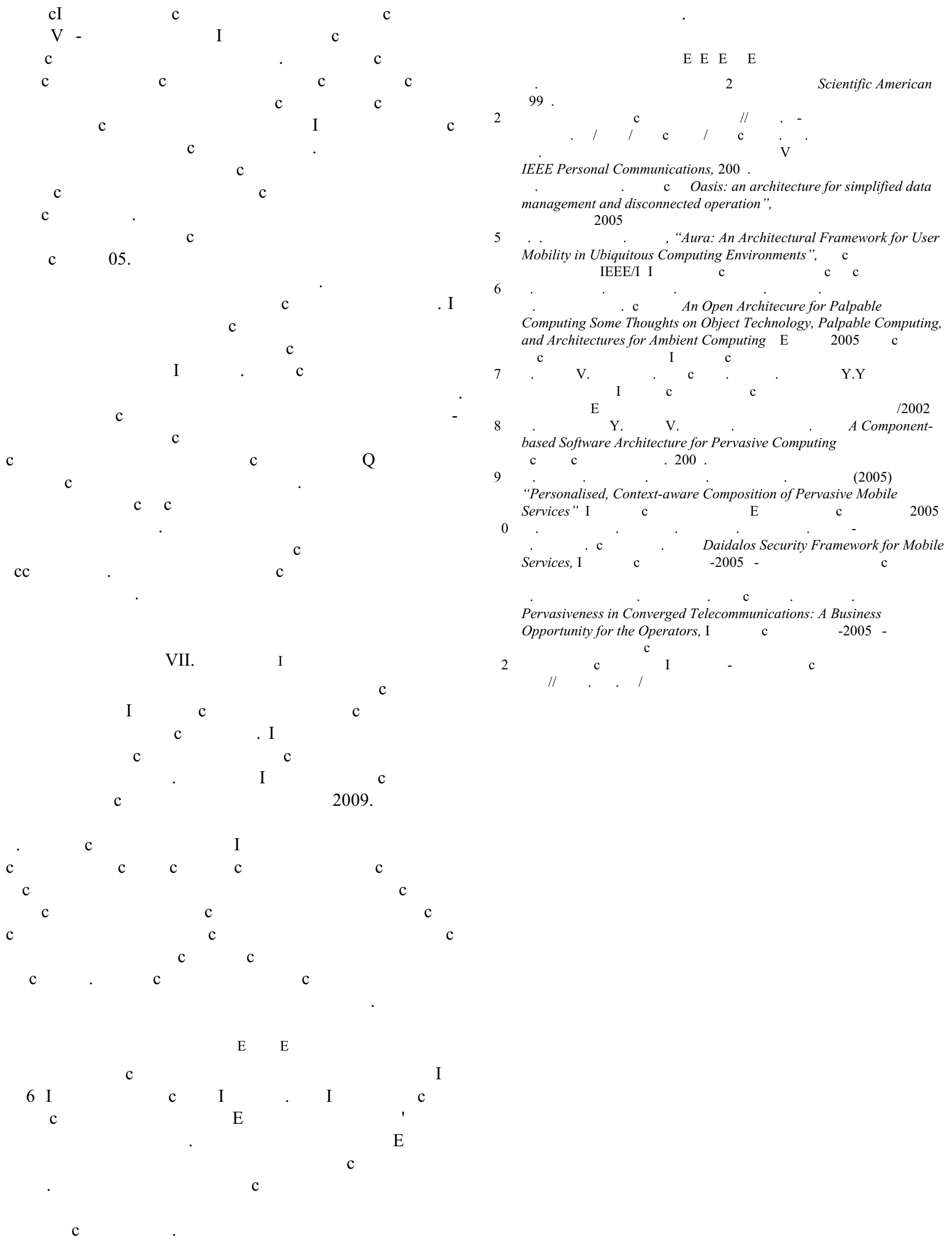

